Fecha de recepción: diciembre 2018 Fecha de aceptación: marzo 2019 Versión final: abril 2019

\section{El casablanquismo, una respuesta a la crisis del funcionalismo}

Damián Sanmiguel *

Resumen: Funcionalismo y arquitectura moderna (AM) suelen estar muy emparentadas en los relatos, análisis y crítica del diseño arquitectónico del siglo XX, casi como dos caras de la misma moneda.

Sin embargo la doctrina funcionalista podemos rastrearla desde tiempos remotos

Palabras clave: Diseño - habitar - tradición - modernidad - identidad - familia.

[Resúmenes en inglés y portugués en la página 82]

${ }^{(*)}$ Doctor en Arquitectura, UBA, Facultad de Arquitectura, Diseño y Urbanismo. (2015) Título de Tesis: "Diseño y Modelización de Programas para la Vivienda de Interés Social, Complejidades y Consecuencias en su aplicación - el caso Matanza Riachuelo". Arquitecto, UBA, Facultad de Arquitectura, Diseño y Urbanismo. (1994)

\title{
Introducción
}

Funcionalismo y arquitectura moderna (AM) suelen estar muy emparentadas en los relatos, análisis y crítica del diseño arquitectónico del siglo XX, casi como dos caras de la misma moneda.

Sin embargo la doctrina funcionalista podemos rastrearla desde tiempos remotos. En el siglo I dc, Vitruvio la definía como uno de sus tres pilares para garantizar la "buena" arquitectura, reforzado por los tratadistas de los siglos XIV, XV y XVI, utilitas, firmitas y venustas tuvieron una vigencia de casi 1700 años.

Pero a mediados del siglo XVIII la triada vitruviana comienza a funcionar de manera descompensada. Las ideas y propuestas de Soane, Ledoux, Boullée y Durand irán más allá de lo prescripto por la triada y de manera exacerbada, en sus definiciones y principios, harán valer una de las partes en relación a las otras dos. (Benévolo, 1977) (Kaufmann, 1974) De los cuatro arquitectos revolucionarios nos vamos a detener en Durand, puesto que es con él donde la doctrina funcionalista toma un impulso sorprendente. 
Para Durand la utilidad es la principal finalidad del diseño arquitectónico. El concepto de utilidad abarcaba tanto la esfera pública como la privada y además debía ser portadora de dos valores intrínsecos, la felicidad y el cobijo, cuestiones que se manifestaban en la espacialidad interior. (Benévolo, 1977)

Ya en el siglo XIX, pero ahora en Inglaterra, volverá a detectarse esta vocación por resaltar la necesidad de hacer edificios que fundamentalmente satisfagan el uso para las cuales fueron creados. Será A.W.N. Pugin quien apoyado en una búsqueda de ideales teológicos sostendrá que la única manera de garantizar belleza en las iglesias es construirlas eficaces para las prácticas anglo católicas.

En los umbrales del siglo XX ya están instaladas las bases para una búsqueda aún más teórica de la dimensión utilitaria del diseño arquitectónico, que además de prestarle atención a los edificios representativos de los poderes hegemónicos de la iglesia y del poder político, palacios y edificios públicos, también incorporará la arquitectura y el equipamiento doméstico. J. L. Petit, a mediados del siglo XIX incluirá en sus propuestas una definición de la arquitectura doméstica "menor" basada en criterios prácticos y exigencias funcionales, restándole protagonismos a elementos ornamentales.

La doctrina funcionalista comenzará a tomar fuerza con las analogías de organismos vivientes, máquinas y funciones biológicas.

De alguna manera ya estaban predispuestos los elementos fundamentales para que Louis Sullivan $(1896,498)$, expresara su famosa fórmula funcionalista: "la forma sigue siempre a la función".

Y de aquí en más un aluvión de teorías, preceptos, críticas, sentencias mesiánicas, fundamentalismos progresistas, relativismos regionales, controversias polarizadas, plagaron el campo discursivo disciplinar a lo largo de todo el siglo XX y por supuesto la historiografía bien se valió de eso, propagando y difundiendo toda clase de preceptos.

Los centros económicos y culturales de Europa y EE.UU. se convirtieron en fuentes inagotables de información. Lo cierto es que la AM encontró en el funcionalismo uno de sus fundamentos más pragmáticos, el otro fundamento fue el racionalismo, hasta creer en 1922 que con la arquitectura "podría evitarse la revolución” (Le Corbusier, 1977).

\section{Desde aquí...}

En nuestras latitudes la visita de Le Corbusier a Buenos Aires, en el 29, sacudió el campo disciplinar y sacó del inconformismo eclecticista a muchos arquitectos ávidos de nuevos horizontes.

Las adhesiones a la "nueva arquitectura" y sus dispositivos de diseño fueron dispares, hubo quienes adoptaron su poética como un recurso más (Iglesia, 1978), dentro de la paleta de estilos posibles y quienes vieron en los principios funcionalistas y racionalistas nuevas y renovadas estrategias de diseño para aspirar a una nueva y saludable forma de vida parael hombre "moderno".

Pero la visita de Zevi, a la Argentina en el 51, sacudirá los principios tranquilazores del "orden" que la AM se esforzaba por instalar y comienzan a difundirse los cuestionamientos. 
La figura de Wright se instala como contrapunto, la fría racionalidad vs. la amigable organicidad, relatos plagados de analogías y reduccionismos intelectualizados sirvieron para sacudir el monopolio funcionalista más ortodoxo.

En otras latitudes, amediados del 50, la cultura y arte POP en Inglaterra y fines del 50 en EE. UU. llevarán adelante una crítica irónica a la sociedad y su modo de expresión artística a través de imágenes populares extraídas de los medios masivos de comunicación.

El Team X conformado por Aldo Van Eyck, Alison y Peter Smithson y Shadrac Woods reconocerán a la ciudad y su entorno particular como casos singulares.

La disolución del CIAM en el 59 puso fin a la vigencia de la Carta de Atenas (1933) siendo reemplazada por la Carta del Hábitat (1953) donde se reconoce el barrio como unidad de identidad, por encima de la vivienda. (Benévolo, 1977)

Los Archigram, a mediados del 60, de la mano de Peter Cook y su Plug-in-city, Ron Herron con The Walking City y Johana Meyer, con The Instant City incorporan a la retórica arquitectónica la alta tecnología, el futurismo y el consumo.

En otro sentido, en 1963, se desarrolla el VII Congreso Internacional de Arquitectos en Cuba, donde entre sus conclusiones fundamentales aparece el reconocimiento del caos urbano, la necesidad de industrializar la construcción, instalar el control democrático de todos los medios de producción y plantear la vivienda como parte de la planificación urbana. A su vez, la Critica Estructuralista a mediados del 60 con autores como Norberg Schulz, Venturi, Aldo Rossi, Lynch, Collins, Rykwert, Bachelard, Eco y otros, aportaran sus cuestionamientos a una arquitectura que parecía estar demasiado ensimismada. En el 68 se desarrolla el simposio de Metodología del Diseño donde se destaca la figura de Christopher Alexander promoviendo un urbanismo participativo.

Es en este contexto global donde germina el "casablanquismo" (CB) como respuesta local, como una toma de posición, como alternativa.

Para adentrarnos en un análisis crítico de la arquitectura y el diseño en general, generado a partir de esta poética debemos tratar de visualizar no solamente sus expresiones formales singulares sino además sus propuestas concretas a una particular manera de entender el habitar.

Es en estas propuestas dónde parece encontrarse los primeros argumentos superadores del binomio forma-función, la hipótesis preliminar es que justamente con el casablanquismo se enriquece la remanida y reduccionista noción de función como generadora de "espacialidad".

La producción del casablanquismo alcanza tanto a viviendas unifamiliares como individuales, iglesias, capillas y hoteles, obras construidas entre 1955 y 1970 aproximadamente. Pero para este trabajo vamos a detenernos solamente en las viviendas unifamiliares debido a que se puede tener acceso a una cantidad de casos que satisfaga la expectativa de información en línea con la hipótesis planteada. 


\section{La forma arquitectónica}

La forma arquitectónica, ¿debe sus características al menos a dos tipos básicos de estructura abstracta o principios de acción? Y estos principios o lógicas ¿̇son interdependientes? ¿Qué tipo de relación existe entre la configuración "envolvente", exterior o volumetría y la organización de su espacialidad o espacialidades "envueltas" o interiores?

Conocidos son y ampliamente estudiados también, la materialidad, el lenguaje y la poética de la AM en la Argentina. Este trabajo no pretende sumar en esa dirección pero sí usar la AM como contrapunto en el análisis del CB y sus propuestas de arquitectura doméstica.

Hablar de arquitectura doméstica es adentrase dentro de las practicas domésticas, prácticas instauradas dentro de un sector específico de la sociedad argentina post ' 50 .

Las demandas de un espacio para estar y comer, para dormir o descansar, para cocinar o bañarse, para entrar o salir parecen ser inamovibles, sin embargo su materialidad, volumetría y definición espacial adquirirán notables transformaciones en comparación con el "status quo" que la AM traía como dispositivos de proyectación.

Lo primero que aparece en los relatos y testimonios de arquitectos y clientes que formaron parte del CB es una particular y determinada definición de "familia".

La casa debía ajustarse a "esa clase de familia" y no a una idea abstracta de familia, a su vez esa clase de familia poseía un gusto determinado, aspiraciones estéticas específicas, ideales y ocupaciones determinados.

Así podemos detectar en la casa Urtizberea, en San Isidro, de 1958, de los arquitectos Caveri y Ellis, las primeras líneas exteriores que caracterizaran a muchas de estas casas, techumbre plana, remarcada horizontalmente por un faldón recto de hormigón visto, muros blancos recortados rítmicamente por los vacíos de las aberturas, chimeneas y ventilaciones encuadradas en esbeltos prismas blancos de albañilería.

En esta misma línea, la casa Cuello, (Fig.1) también en San Isidro, de 1963, de los arquitectos Álvarez, Serra, Rusiñol y D'Alessandro incorpora detalles de columnas y vigas en madera, enmarcando la composición de la fachada, y aberturas apaisadas que llegan al dintel.

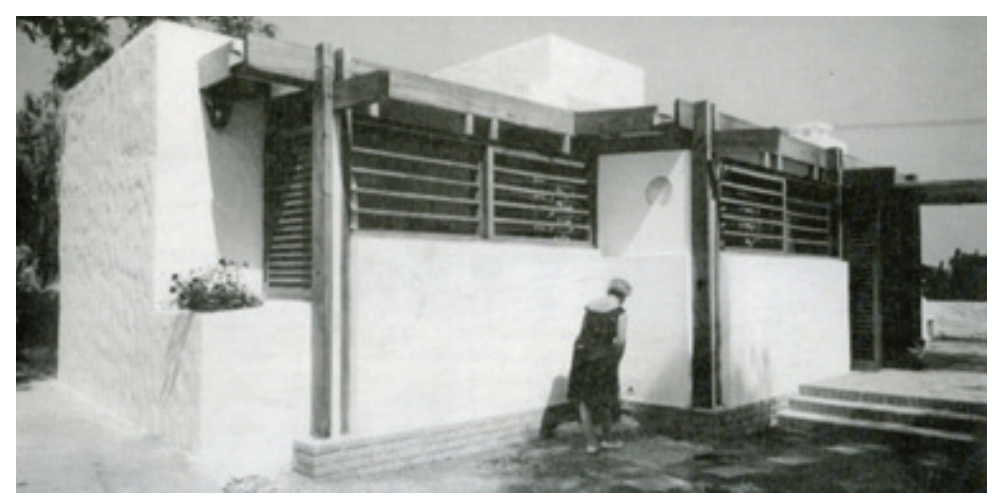

Figura 1. Fuente: CEDODAL 
La casa Demaría del grupo Onda, en 1958, propone la solución abovedada para la cubierta, llevando hacia el exterior el hormigón visto como cierre de la bóveda, retrasando el muro adyacente y generando una buña en el apoyo de la bóveda.

En Tucumán, la casa Piñero, de 1971 del propio arquitecto, alterna entre las dos soluciones volumétricas, la bóveda se acopla a una galería rematada por un faldón recto de hormigón visto, y el resto de los ambientes son tratados como volumetrías prismáticas.

La presencia exterior de la bóveda toma notoriedad en la casa Lapacó, de 1960, del arquitecto Bidinost. Aquí una sucesión de tres bóvedas de cañón constituyen una galería hacia el jardín rematadas por prismas rectos. Y si bien los arcos señalan un ritmo curvilíneo la composición general tiene una marcada horizontalidad.

La bóveda se manifiesta aún con más presencia en la casa Ricciardi, de 1962, del arquitecto Ruiz Martínez. Aquí la planta alta rompe con la horizontalidad volumétrica, ofreciéndole al conjunto una porción desmesurada de muro que remata con la misma solución de techumbre. Todos los muros adyacentes al largo de la bóveda de la planta baja están retrasados y son los que poseen aberturas.

Por ultimo vale destacar dentro de las principales tendencias volumétricas la casa Ellis, en Altos del Talar, Pacheco, de 1958, del propio arquitecto. Aquí la volumetría se desmarca de todo lo visto, cada espacialidad es tratada con independencia volumétrica a través de un techo a dos aguas y remarcando perimetralmente por faldones de hormigón visto que toman la pendiente y los tramos rectos. La volumetría de la planta alta queda mejor resuelta que en el caso anterior evitando una desproporcionada superficie muraria.

Otro ejemplo de techo en pendiente y azotea plana lo constituye la casa Goldstein, en Pinamar, de 1968, del arquitecto Bidinost. Aquí la casa se presenta con dos caras, una hacia el mar, ofreciendo una volumetría compacta y delimitada por la techumbre inclinada, contenida por un faldón recto, que a su vez es marcada rítmicamente por muros que dividen en cinco paños fijos verticales el aventamiento. Y otra cara de marcada horizontalidad que balconea hacia el acceso.

Resumiendo, podemos decir que las volumetrías exteriores de los ejemplos mencionados, aparecen como expresiones resultantes de una energía interior, con improntas del ADN racionalista pero reelaboradas. Bóvedas, prismas, pirámides o faldones rectos de hormigón visto se convertirán en el repertorio más recurrente. Pero debe destacarse que estas volumetrías muchas veces aparecen ensambladas en una misma casa, la "forma" resultante ha dejado de ser una expresión de "pureza geométrica" y se ha convertido en una yuxtaposición elaborada.

Habiendo analizado estos exteriores y comprendido sus volumetrías generales, ¿podemos establecer alguna correspondencia con sus espacios interiores y aún más, con el equipamiento de ellos mismos?

Revisando los interiores de estas casas efectivamente encontramos un tratamiento recurrente. Materiales, detalles constructivos, texturas, colores y equipamiento se articulan en cada una de ellas de manera singular pero con una misma impronta.

La sala de estar de la casa Ricciardi es dominada por la bóveda de cañón, con ladrillos a la vista, el muro de apoyo es recortado por una abertura hasta el propio dintel sobrepasando notoriamente la altura estándar de los vanos. Los muros interiores adyacentes van recortándose y abriéndose permitiendo armar el hogar, nichos y aberturas anticipan 
ambientes contiguos. Muebles, detalles en madera y texturas rugosas terminan generando un ambiente de calidez envolvente.

En el interior de la casa Goldstein hay una apuesta de trabajar con la luz cenital que ilumina el estar-comedor de tal forma que le otorga una dinámica espacial apoyada en los contrastes de luz y sombra entre los medios niveles del interior. A su vez esos medios niveles tienen expansiones que se convierten en terrazas o patios que se acomodan a los médanos existentes.

Una imagen de la caja de escalera de la casa Ruppel (Fig. 2) del arquitecto Ruiz Martínez refuerza la utilización de recursos análogos. La caja de escalera se presenta totalmente transparente, el muro que sostiene la viga principal del techo es perforado dejando entrar la luz desde arriba y en su parte inferior es rehundido permitiendo un hueco para el hogar.

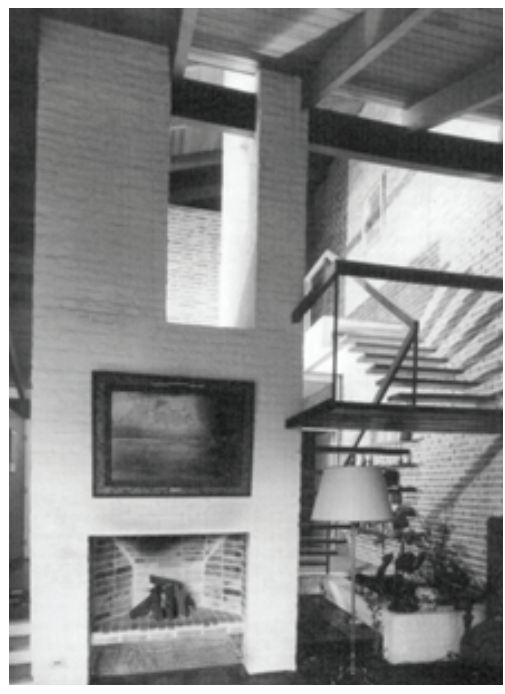

Figura 2

Fuente: Revista Nuestra Arquitectura $\mathrm{N}^{\circ} 432$

En el estar comedor de la casa Piñero encontramos otra variante del espacio abovedado, aquí la viga horizontal que toma el empuje de la bóveda se transforma en un elemento horizontal que sectoriza el ambiente y demarca la circulación adyacente a las ventanas. Podemos ver que el diseño de los interiores es resultante de espacialidades perforadas o delimitadas virtualmente, cajas de escaleras huecas, cocinas comedor que se integran al estar, galerías que tamizan la relación interior-exterior, paredes interiores que no llegan al techo abovedado, sectores para sentarse del estar sobre mampostería, chimeneas caladas en los muros, mesas empotradas que arman un lugar de comedor diario, combinación de mobiliario fijo y móvil para delimitar espacios.

Pisos, paredes y techos con texturas rugosas, alfombras, cuadros, macetas interiores, pérgolas, galerías con media sombra.Todos recursos materiales que dan como resultado un 
espacio interior extremadamente virtuoso, que se descubre de apoco, que ofrece zonas más opacas, traslucidas o rincones luminosos. Es justamente en el tratamiento de la luz y la manera en la que ella se tamiza como se demuestra esta particular manera de entender nuestro clima. Nada de paños vidriados al filo y continuos y su efecto invernadero.

\section{La forma objetual}

Como dijimos, el diseño del espacio interior es acompañado, configurado definitivamente por una cantidad de objetos que se disponen de tal manera que completan los aspectos generales de la poética CS.

Efectivamente la elección de los materiales, las formas dispuestas, los colores, las texturas y su manufactura, estarán reforzando los presupuestos ideológicos y disciplinares.

El testimonio del arquitecto Juan María D'Alessandro (2003) es esclarecedor,

"el lenguaje de las Casa Blancas tiene una enorme coherencia entre forma y contenido: los espacios acompañan, se enriquecen con su uso y son definidos por terminaciones como bolseados,... volumetrías que hablan de interioridades" (p.170)

$\mathrm{Al}$ respecto de los objetos del equipamiento agrega:

"Una mesa era dos pilares de mampostería con una tapa de madera maciza, los asientos eran ensanchamientos de paredes en torno a de chimeneas y lugares de reunión. Las camas tenían cabeceras de mampostería con largueros de madera." (p.171)

Era muy clara la adhesión a la economía de recursos, a lo austero, a la mano de obra artesanal y a los programas singulares. La vocación por el detalle era una declaración de principios:

"Cuando me dispongo a diseñar una mesa, razono: estructura de sostén y tapa. Así eran. Para entenderlas había que darlas vuelta. Y aparecían elementos espurios. Conscientemente busco que todo se vea. Las cabezas de las patas y los largueros pasan a ser parte de la tapa y esta queda entre ellos... mejoro la relación asiento mesa, haciéndola 45/72 cm." (p.172)

Del testimonio de D’Alessandro puede inferirse la manera en que el diseño objetual busca insertarse en una poética que le determina una materialidad específica.

La casa Cuello es un buen ejemplo de esta relación intrínseca entre diseño objetual, espacio interior y volumetría exterior. 


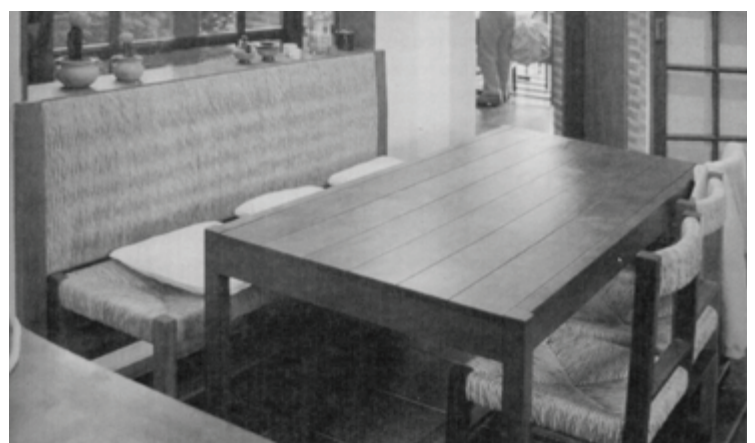

Figura 3. Fuente: CEDODAL

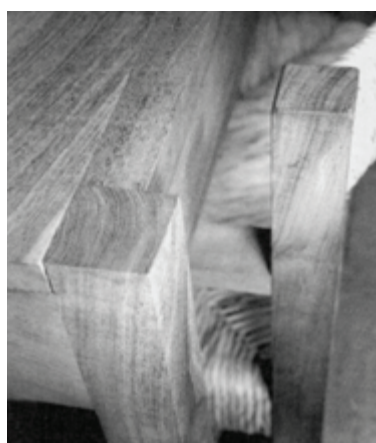

Figura 4. Fuente: CEDODAL

Ese cuidado y detallismo en el diseño de los ensambles de la mesa del comedor diario (Fig.4) puede verificarse también en los ensambles y encuentros de las vigas y columnas de madera que arman la pérgola de la expansión.

La textura de paja de las sillas (Fig.3) se emparenta con la textura que le imprimen las cañas utilizadas en la cobertura de la pérgola (Fig. 5). Filtrando la luz del semicubierto, superficies rugosamente artesanales en el interior y en el exterior, cerramientos de vidrio rehundidos y protegidos que tamizan la luz.
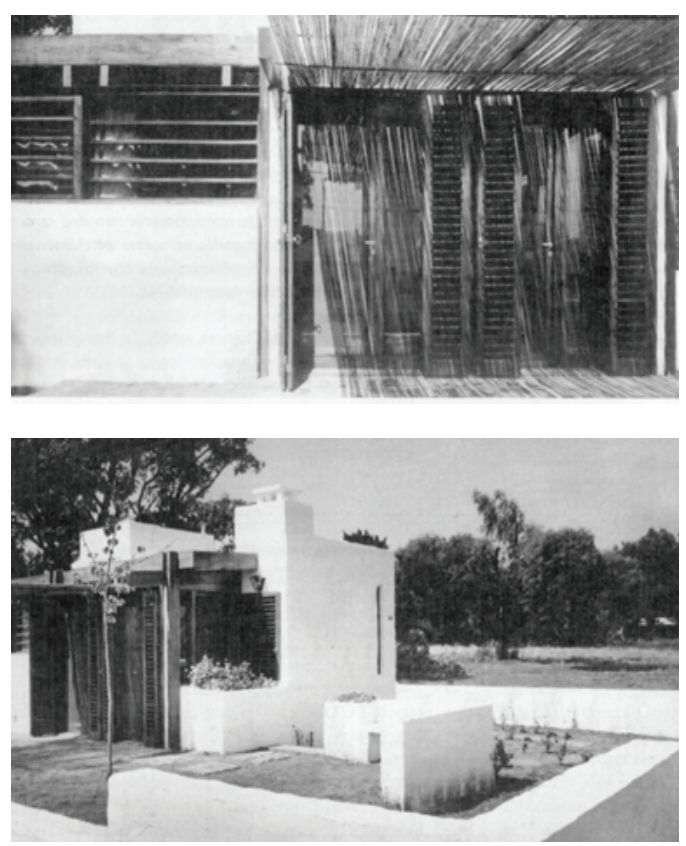

Figura 5. Fuente: CEDODAL

Figura. 6. Fuente: CEDODAL 
El diseño de los espacios, tanto exteriores (Fig. 6) como interiores se caracterizan por ser sociópatas, por tener una disposición que permite la reunión, la estancia, el tener ganas de quedarse. Claramente las conformaciones, tanto espaciales como objetuales posibilitan o restringen determinadas conductas (Doberti, 1999) y estos grados de libertad son los que caracterizan las prácticas sociales y nos ofrecen una propuesta de habitar.

El ámbito comedor estará determinado por una particular disposición de la mesa y las sillas, la relación métrica entre ellos es resultante de una búsqueda experimental y no de una idea abstracta de relaciones proporcionales o de tendencias mercantilistas. La materialidad de los objetos esta en concordancia con los materiales que constituyen la espacialidad, texturas y colores son convergentes a la idea de calidez y simpleza.

Es recurrente encontrar en los testimonios de quienes encargan estas casas o de quienes las diseñan una marcada preferencia por el detalle artesanal, una clara demostración de recurrir al diseño "no standard", no mecanizado.

\section{Reflexiones}

Relevando la poética del CS podemos detectar como estas caracterizaciones del diseño arquitectónico y objetual que hemos detallado han tenido una aplicación recurrente, la exposición de las 14 casas así lo demuestra.

En línea con nuestra hipótesis preliminar podemos agregar que la crisis del funcionalismo permitió la búsqueda de nuevos dispositivos de diseño, pero no significó un abandono de las teorías funcionalistas, más bien le dio una nueva connotación.

Lejos de la típica analogía con un revival colonial teñido de cierta carga peyorativa o de una búsqueda de "argentinidad" en el vasto horizonte de nuestra mixtura cultural podemos ver que el CS se concentró en una genuina búsqueda de alternativas proyectuales con una fuerte carga ideológica.

Arquitectos y clientes estaban más emparentados de lo que uno podría suponer, un "habitus" determinado los alineaba en una constelación de fenómenos económicos, culturales, ideológicos y políticos (Bourdieu, 1997) que dieron sentido a las demandas y a las propuestas.

\section{Lista de Referencias Bibliográficas}

Álvarez, R. - Rusiñol, J. - Serra, F. - D'Alessandro, J. (1965). “Vivienda en Pla.cido Marin 764, Boulogne" En Revista Nuestra Arquitectura No 428, septiembre de 1965, Buenos Aires, pp. 35-38

Benévolo, L.(1977) Historia de la Arquitectura Moderna, Barcelona, España, Editorial Gustavo Gili

Bourdieu, P. (1997). Razones Prácticas. Barcelona, España, Ed. Anagrama.

Caveri, C. -Ellis, E. (1986) “Casa Urtizberea, Juan Clark 157, San Isidro” En Revista Summa $N^{o} 231$, noviembre de 1986, Buenos Aires, pp. 34-35

D'Alessandro, J. M. (2003). “Una mirada visceral”. En Gutiérrez, R. (Ed.), Casas Blancas, una propuesta alternativa. (pp. 170-174). Buenos Aires, Argentina, Ed. CEDODAL. 
Doberti, R. (1999) “De la descripción de costumbres a una teoría del habitar". En Giordano, L. - D'Angeli, L. (Ed.), El habitar, una orientación para la investigación proyectual. (pp. 23-54). Buenos Aires, Argentina, Ed. Laboratorio de Morfología FADU-UBA.

Grupo Onda: Asencio, M.l - Garat, J. - Gigli, L.- Iglesia, Rafael (1963). "Vivienda con bóvedas catalanas en San Fernando, Máximo Perez y Maestro Alvarez. Casa De María”. En Revista Nuestra Arquitectura No 403, junio de 1963, Buenos Aires, pp., 16-20

Iglesia, Rafael. E. J.et al (1978). "La reacción antiracionalista de las casas blancas”. En Iglesia, Rafael E. J. (Coord.) (1978), Buckminster Fuller; Archigram \& Co. ; La reacción antirracionalista de las casas blancas, Buenos Aires, Argentina, Editorial Espacio, pp. 53-78.

Iglesia, R. E. J (1979) "Vida familiar y espacio interior" En Revista Nuestra Arquitectura $N^{o}$ 509, diciembre de 1979, Buenos Aires, pp. 16-17

Kaufmann, E- (1974) La Arquitectura de la Ilustración. De Ledoux a Le Corbusier: orígenes $y$ desarrollo de la arquitectura moderna, Barcelona, España, Editorial Gustavo Gili.

Le Corbusier (1977) Hacia una arquitectura, Buenos Aires, Editorial Poseidón.

Rickert, S. - Bozzano, J. (2014) Eduardo Ellis. Espacio arquitectónico y escala humana. Buenos Aires, Ediciones del autor.

Ruiz Martínez, F.(1966) “Casa en Borges 1189, Olivos” En Revista Nuestra Arquitectura No 432, julio de 1966, Buenos Aires, pp. 36-41.

Ruiz Martínez, F. (1969) “Casa Laprida 212, San Isidro” En Revista Nuestra Arquitectura $N^{o} 457$, marzo de 1969, Buenos Aires, pp. 18-21.

Sullivan, L. (1896) “The tall office building artistically considered” en Lippincott's Magazine volume 339, marzo de 1896, Filadelfia, Estados Unidos de Norteamérica, pp. 403-409. Disponible en: https://archive.org/details/tallofficebuildi00sull/page/n9

\begin{abstract}
Functionalism and modern architecture (MA) are closely related to stories, analysis and criticism of twentieth century architectural design, almost like two sides of the same coin. However, the functionalist doctrine can be also traced from remote times.
\end{abstract}

Keywords: Design - live - tradition - modernity - identity - family.

Resumo: Funcionalismo e arquitetura moderna (AM) são geralmente intimamente relacionados nas contas, análise e crítica do projeto arquitetônico do século XX, quase como dois lados da mesma moeda. No entanto, a doutrina funcionalista pode ser traçada desde tempos remotos.

Palavras chave: Design - vida - tradição - modernidade - identidade - família.

[Las traducciones de los abstracts fueron supervisadas por el autor de cada artículo] 